\title{
Factor VIII-East Hartford (Arginine 1689 to Cysteine) Has Procoagulant Activity When Separated from von Willebrand Factor
}

\author{
Ashraf M. Aly and Leon W. Hoyer \\ Holland Laboratory, American Red Cross Blood Services, Rockville, Maryland 20855
}

\begin{abstract}
Factor VIII East Hartford (FVIII-EH) procoagulant activity is reduced because the substitution of cysteine for arginine 1689 abolishes an essential Factor VIII light chain thrombin cleavage site. Incubation of FVIII-EH plasma with penicillamine or DTT causes a five- to sixfold increase in FVIII-EH VIII:C, at 80 and $1 \mathrm{mM}$, respectively. While there is no FVIII-EH light chain cleavage when thrombin is added in the presence of penicillamine or DTT, these reducing agents disrupt the FVIII-vWf complex. For example, the addition of $5 \mathrm{mM}$ DTT to normal or FVIII-EH plasma causes a 50\% reduction in Factor VIII binding to vWf. These observations suggested that DTT increases FVIII-EH VIII:C by partial dissociation of FVIII-EH from vWf. This was verified by showing that vWf-free FVIII-EH had VIII:C activity of $21 \mathrm{U} / \mathrm{dl}$, while the starting plasma level was $2.5 \mathrm{U} / \mathrm{dl}$. Removal of other FVIII-EH plasma proteins by agarose gel filtration had no effect on VIII:C activity. The demonstration that this mutant Factor VIII has cofactor function when separated from $v W f$ indicates that the dissociation of Factor VIII from vWf is an essential effect of Factor VIII light chain cleavage at arginine-1689. (J. Clin. Invest. 1992. 89:1382-1387.) Key words: hemophilia A • penicillamine $\bullet$ dithiothreitol $\bullet$ cysteamine $\bullet$ crossreacting material
\end{abstract}

\section{Introduction}

Hemophilia A is a common hereditary bleeding disorder caused by a deficiency of Factor VIII procoagulant activity. Factor VIII plays a crucial role in the intrinsic pathway of blood coagulation as a cofactor for the activation of Factor $\mathrm{X}$ by Factor IXa in the presence of $\mathrm{Ca}^{2+}$ and phospholipid $(1,2)$.

In plasma, Factor VIII and vWf, a high molecular weight multimeric glycoprotein, circulate in a noncovalent complex. This association is very important, as it is believed that vWf is required for Factor VIII production $(3,4)$ and stabilization $(5$, 6). Studies have localized the binding site of $\mathrm{vWf}$ to the $\mathrm{NH}_{2}$-terminal portion of the Factor VIII light chain. This was established most directly by the demonstration that a modified Factor VIII, in which amino acid residues 1666-1689 are deleted,

This work was presented in part at the 13th Congress of the International Society on Thrombosis and Haemostasis, Amsterdam, July, 1991. A. M. Aly performed this work in partial fulfillment of the Ph.D. requirements in the Graduate Genetics Program at the George Washington University.

Address reprint requests to Dr. Leon Hoyer, Holland LaboratoryARCBS, 15601 Crabbs Branch Way, Rockville, MD 20855.

Received for publication 19 August 1991 and in revised form 30 December 1991.

J. Clin. Invest.

(c) The American Society for Clinical Investigation, Inc.

$0021-9738 / 92 / 05 / 1382 / 06 \$ 2.00$

Volume 89, May 1992, 1382-1387 does not bind vWf (7). In addition, monoclonal anti-Factor VIII antibodies that bind to Factor VIII light chain amino acid residues 1670-1689 inhibit Factor VIII binding to vWf $(8,9)$. The localization of this site clarifies the requirement of an intact Factor VIII light chain for vWf binding. Thus, thrombin cleavage at residue 1689 , separating a peptide containing residues 1649-1689 from the remainder of the light chain, dissociates the Factor VIII/vWf complex (10-14).

Plasma Factor VIII itself is a population of heterodimers, each of which contains an $80-\mathrm{kD}$ light chain in metal ion linkage with a variable-sized (92-210 kD) heavy chain. Most studies suggest that thrombin cleavages at light chain arginine-1689 and heavy chain arginine-372 are required for Factor VIII activation to an effective cofactor protein (15). A central question is whether light chain cleavage is essential only for the dissociation of Factor VIII from vWf, or if it is an intrinsic requirement for FVIII activity. This issue has been studied by Hill-Eubanks, Parker, and Lollar, using a snake venom protease that generates a thrombin-like cleavage of the porcine Factor VIII heavy chain, but that does not cleave the light chain (16). These investigators showed that porcine Factor VIII procoagulant activity can be generated by heavy chain cleavage alone if vWf is removed. Consistent with that observation, porcine vWf inhibited the VIII:C function of venom enzyme-activated porcine Factor VIII, but it had no effect on thrombin-activated Factor VIII. For this reason, Hill-Eubanks et al. suggested that the essential role of light chain cleavage is the dissociation of the vWf/Factor VIII complexes (16).

We have examined this issue in a different way, using a mutant Factor VIII-designated Factor VIII East Hartford (FVIII-EH), ${ }^{1}$ in which the substitution of cysteine for arginine1689 abolishes a light chain thrombin cleavage site (17). Factor VIII-EH is an example of a dysfunctional, but immunologically detectable, FVIII-like protein that is present, at levels comparable with those in normal plasma, in $5 \%$ of patients with hemophilia A $(18,19)$. Such plasmas are termed cross-reacting material positive (CRM-positive).

The effect of cysteamine (beta-mercaptoethylamine) on apolipoprotein E-2, another mutant protein with a cysteine for arginine substitution (20), initially led us to examine the effect of this compound on FVIII-EH. When it was found that cysteamine caused a 14-fold increase in Factor VIII procoagulant activity (21-23), other reducing agents were tested to determine the specificity of the effect. These studies showed that DTT and penicillamine cause a consistent five- to sixfold increase in VIII:C activity, but the mechanism of action appeared to be quite different from that of cysteamine. While the cyste-

1. Abbreviations used in this paper: BBS, barbital buffered saline; CRM, cross-reacting material; DFP, diisopropyl fluorophosphate; VIII:Ag, Factor VIII antigen; VIII:C, Factor VIII procoagulant activity; FVIII-EH, Factor VIII East Hartford; IA, iodoacetamide; NPP, normal pooled plasma; TBS, tris-buffered saline; $\mathrm{V}_{0}$, void volume; vWf:Ag, von Willebrand factor antigen. 
amine-treated FVIII-EH is cleaved by thrombin at residue 1689 , presumably because cysteamine generates a mixed disulfide (cysteine-1689: cysteamine) that has "pseudolysine" properties $(21,23)$, neither DTT nor penicillamine support FVIIIEH light chain cleavage by thrombin. We report here further studies that demonstrate that the increase in FVIII-EH procoagulant activity produced by DTT is a result of the dissociation of the mutant protein from vWf. Additional experiments with this mutant protein further delineates the role of light chain cleavage in Factor VIII cofactor function.

\section{Methods}

Materials. The characteristics of the CRM-positive hemophilia A plasmas and the clinical data for patients ARC- 5 and ARC-10 have been described in a previous report (17). All studies were carried out with ARC-5 plasma, and comparable results were obtained for selected critical points, using ARC-10 plasma.

Cysteamine $\mathrm{HCl}$ (2-mercaptoethylamine), D-L-DTT and penicillamine were purchased from Sigma Chemical Co. (St. Louis, MO). Diisopropyl fluorophosphate (DFP) was purchased from Aldrich Chemical Co. (Milwaukee, WI). All chemicals were kept desiccated at $4^{\circ} \mathrm{C}$ until they were dissolved at $150 \mathrm{mM} \mathrm{NaCl} / 20 \mathrm{mM}$ Tris- $\mathrm{HCl}, \mathrm{pH} 7.4$ (TBS). These solutions were then stored at $4^{\circ} \mathrm{C}$. Monoclonal anti-Factor VIII light chain antibody ESH-8 was purchased from Amer. Diagnostica Inc. (Greenwich, CT). Factor VIII concentrate (antihemophilic factor [human], Method M, monoclonal purified) was obtained from American Red Cross Blood Services.

Factor VIII measurements. Factor VIII procoagulant activity (VIII:C) was measured by a one-stage assay using Factor VIII-deficient plasma as substrate (24), and by a chromogenic substrate assay of Factor Xa production (25). Factor VIII antigen (VIII:Ag) was measured by immunoradiometric assay using ${ }^{125}$ I-labeled $\mathrm{Fab}^{\prime}$ prepared from the plasma of a patient with an alloantibody to Factor VIII (19). von Willebrand Factor antigen (vWf:Ag) was measured by immunoradiometric assay using a rabbit antibody (26). Citrate-anticoagulated normal plasma, pooled from 15 healthy donors, was used as a standard (1 $\mathrm{U} / \mathrm{ml}$ ) for VIII:C, VIII:Ag, and vWf:Ag measurements.

Determination of VIII:C activity in samples incubated with reducing agents. Plasmas or column fractions were incubated with an equal volume of the reducing agent in barbital buffered saline (BBS) (19), or BBS alone, at $37^{\circ} \mathrm{C}$ for $30 \mathrm{~min}$. VIII:C activity was then determined for the mixtures by a one-stage coagulation assay or by a chromogenic substrate assay. A mixture of normal plasma and an equal volume of BBS incubated under the same conditions was the standard used to calculate VIII:C activity.

Evaluation of thrombin cleavage at arginine-1689 in plasmas incubated with reducing agents. Mixtures of normal or FVIII-EH plasmas that had been incubated at room temperature for $16 \mathrm{~h}$ with immunoadsorbent (anti-Factor VIII inhibitor IgG-agarose) beads were then incubated for $30 \mathrm{~min}$ at $37^{\circ} \mathrm{C}$ with cysteamine, DTT, or penicillamine ( 10 $\mathrm{mM}, 1 \mathrm{mM}$, and $80 \mathrm{mM}$ final concentrations, respectively). The beads were subsequently washed and processed in the standard way (27).

Binding of Factor VIII to von Willebrand factor. Citrate-anticoagulated plasmas, sera, or mixtures of a Factor VIII concentrate with normal vWF (CRM-negative hemophilic plasma) $(0.2 \mathrm{ml})$ were incubated for $1 \mathrm{~h}$ at $37^{\circ} \mathrm{C}$ with ${ }^{125}$ I-labeled ESH-8 anti-FVIII monoclonal antibody $(35,000 \mathrm{cpm})$. The samples were then applied to a 1.6 $\times 60$-cm Sepharose-6B column preequilibrated with TBS. The gel filtration was carried out at a flow rate of $22 \mathrm{ml} / \mathrm{h}, 3-\mathrm{ml}$ fractions were collected, and radioactivity determined using a multirack gamma counter (LKB Instruments Inc., Gaithersburg, MD). The amount of radiolabel in void volume ( $\mathrm{Vo})$ fractions was used as a measure of Factor VIII bound to vWf.

Sera were prepared from plasmas by two additions of highly purified human thrombin $\left(3 \mathrm{U} / \mathrm{ml}\right.$ plasma) and incubation at $37^{\circ} \mathrm{C}$ for 30 min before fibrin removal.
The effect of reducing agents on Factor VIII binding to vWf was determined by incubating cysteamine or DTT $(10 \mathrm{mM}$ or $1 \mathrm{mM}$ final concentration, respectively) with $0.2 \mathrm{ml}$ plasma or serum for $30 \mathrm{~min}$ at $37^{\circ} \mathrm{C}$ before the addition of ${ }^{125} \mathrm{I}$-labeled monoclonal antibody. In some experiments, iodoacetamide (IA), ( $20 \mathrm{mM}$ final concentration) was added after the reducing agent, the plasma or serum held at $37^{\circ} \mathrm{C}$ for an additional $30 \mathrm{~min}$, and the mixture was dialyzed against excess (2 changes of 2 liters) BBS for $2 \mathrm{~h}$ to assure complete removal of free chemicals. The labeled antibody was then added to the treated plasma. Normal vWf (0.2 ml CRM-negative hemophilic plasma) was added to some reduced and alkylated samples after the dialysis step, and the mixture was incubated for $1 \mathrm{~h}$ at $37^{\circ} \mathrm{C}$ before the labeled monoclonal antibody was added.

Preparation of $v W f$-free Factor VIII. We have previously described a method for preparing vWf-free Factor VIII (28). In brief, a 5-ml column of agarose beads coupled with rabbit anti-human vWf IgG was perfused with $5 \mathrm{ml}$ of plasma with recirculation at room temperature for $16 \mathrm{~h}$, unadsorbed proteins were removed by washing the beads with BBS, and vWf-free FVIII was eluted with BBS containing $240 \mathrm{mM}$ $\mathrm{CaCl}_{2}, 2 \mathrm{mM} \mathrm{DFP}$, and $1 \mathrm{mg} / \mathrm{ml} \mathrm{BSA}$. Fractions were assayed for VIII:C by a chromogenic substrate assay (25), and for FVIII:Ag (19) and vWf:Ag (26).

Preparation of $v W f$-Factor VIII complexes. Cryoprecipitate was prepared from $5 \mathrm{ml}$ frozen plasma by gradual thawing in an ice bath. The vWf-rich precipitate obtained by centrifugation was then brought to $0.5 \mathrm{ml}$ with $\mathrm{BBS}$ and chromotographed at room temperature over a $1.6 \times 60 \mathrm{~cm}$ Sepharose $6 \mathrm{~B}$ column equilibrated with BBS. The flow rate was maintained at $22 \mathrm{ml} / \mathrm{h}$, and fractions were assayed for VIII:C (chromogenic assay), VIII:Ag, and vWf:Ag. As expected, vWf Factor VIII complexes were restricted to the Vo fractions.

\section{Results}

Effect of reducing agents on FVIII-EH activity and thrombin cleavage at arginine-1689. Dose-dependent enhancement of Factor VIII:C was documented when penicillamine or DTT were added to FVIII-EH plasma, with sixfold increases at optimum concentrations of $80-100 \mathrm{mM}$ and $1 \mathrm{mM}$, respectively (Figs. 1 and 2). We then carried out a series of experiments to determine the mechanism by which DTT and penicillamine increase FVIII-EH VIII:C activity. The initial effort was to determine if these compounds support thrombin cleavage of the FVIII-EH light chain at residue 1689. Similar studies were carried out with cysteamine $(21,22)$, as well as penicillamine and DTT, but the results were strikingly different: only cysteamine induced thrombin cleavage of the FVIII-EH light chain (Fig. 3, lane 2). Concentrations of penicillamine and DTT that maximally enhance VIII:C activity $(80$ and $1 \mathrm{mM}$, respectively) had no effect on FVIII-EH light chain cleavage (lanes 3 and 4). As expected, Factor VIII heavy chain cleavage was

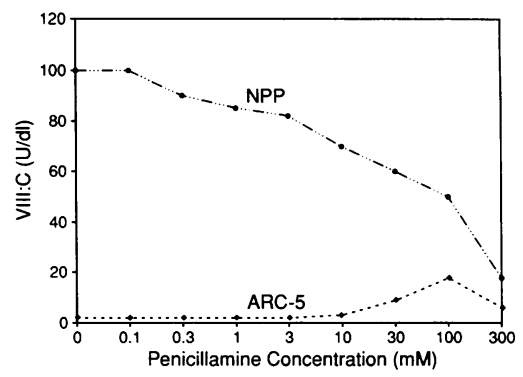

Figure 1. Effect of penicillamine on VIII:C activity. Mixtures of FVIII-EH $(A R C-5)$ or normal pooled plasma $(N P P)$ with penicillamine (final concentrations indicated) were incubated at $37^{\circ} \mathrm{C}$ for 30 min before VIII:C measurement by a onestage coagulation assay.

Comparable results were obtained at 0 and $100 \mathrm{mM}$ with ARC-10. 


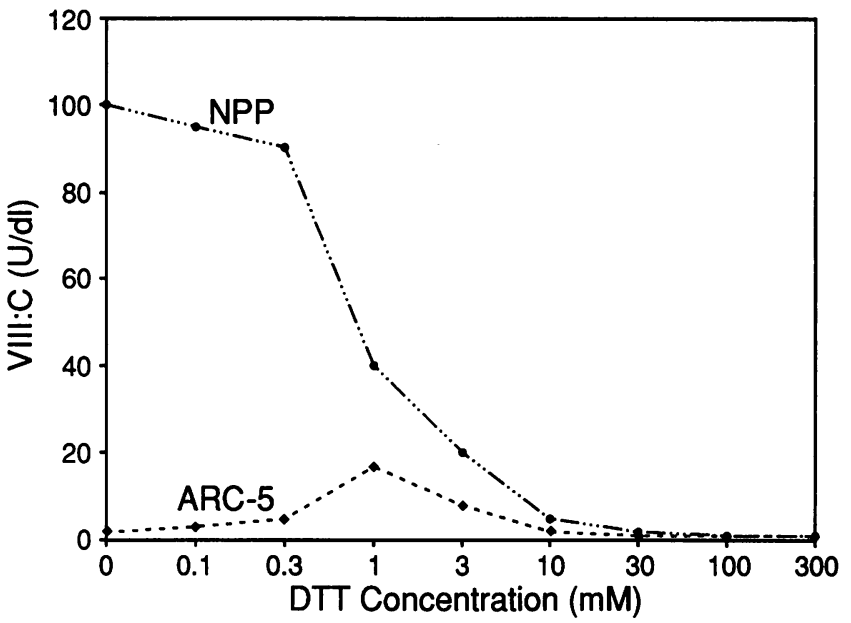

Figure 2. Effect of dithiothreitol (DTT) on VIII:C activity. Mixtures of FVIII-EH $(A R C-5)$ or normal pooled plasma $(N P P)$ with $D T T$ (final concentrations indicated) were incubated at $37^{\circ} \mathrm{C}$ for $30 \mathrm{~min}$ before VIII:C measurement by a one-stage coagulation assay. Comparable results were obtained at 0 and $1 \mathrm{mM}$ with ARC- 10 .

normal in the presence of all of the reducing agents tested. Previous experiments have shown that this method can detect Factor VIII-EH light chain cleavage when as little as $10 \%$ of the light chain is converted to the $72-\mathrm{kD}$ fragment (17).

Effect of reducing agents on the Factor VIII-vWf interaction. As an intact Factor, VIII light chain is necessary for the maintenance of the Factor VIII-vWf complex $(10,12,14)$; the effect of these chemicals on the stability of the Factor VIII-vWf complex was then examined to determine if a more sensitive measure of light chain cleavage could be established. By measuring the Factor VIII elution profile on $6 \%$ agarose gel filtration, we determined the effect of the reducing agents on FVIIIEH association with vWf. While Factor VIII complexed with vWf elutes in Vo fractions, thrombin-activated Factor VIII elutes in later fractions, as it does not contain a vWf binding site (29). An anti-Factor VIII monoclonal antibody (ESH-8) was used to identify Factor VIII in these experiments. Preliminary studies demonstrated that this antibody does not affect the Factor VIII-vWf interaction. While normal serum (thrombin-treated plasma in these experiments) had much less Vo Factor VIII than normal plasma from which it was prepared, ( $83 \%$ reduction, Table $\mathrm{I}$ ), the addition of thrombin had little effect on the amount of FVIII-EH in Vo fractions (Table I). As expected (21-23), the reduction in Vo FVIII-EH was similar to that for normal plasma Factor VIII when cysteamine was added before thrombin treatment (Table I). Cysteamine added to plasma, in the absence of subsequent thrombin treatment, had little effect on the amount of Factor VIII in Vo fractions.

Very different results were obtained when plasmas were incubated with DTT instead of cysteamine before thrombin treatment and/or gel filtration. Addition of $5 \mathrm{mM}$ DTT to either normal or FVIII-EH plasma reduced the Vo Factor VIII by about $50 \%$. The addition of thrombin to DTT-treated normal plasma further reduced the Vo Factor VIII to $21 \%$, but it had no effect on DTT-treated FVIII-EH plasma (Table I).

In order to better understand the DTT effect, IA was added to plasma previously incubated with DTT. After dialysis to remove residual IA and DTT, very little Factor VIII remained in Vo fractions for both normal and FVIII-EH plasmas. This

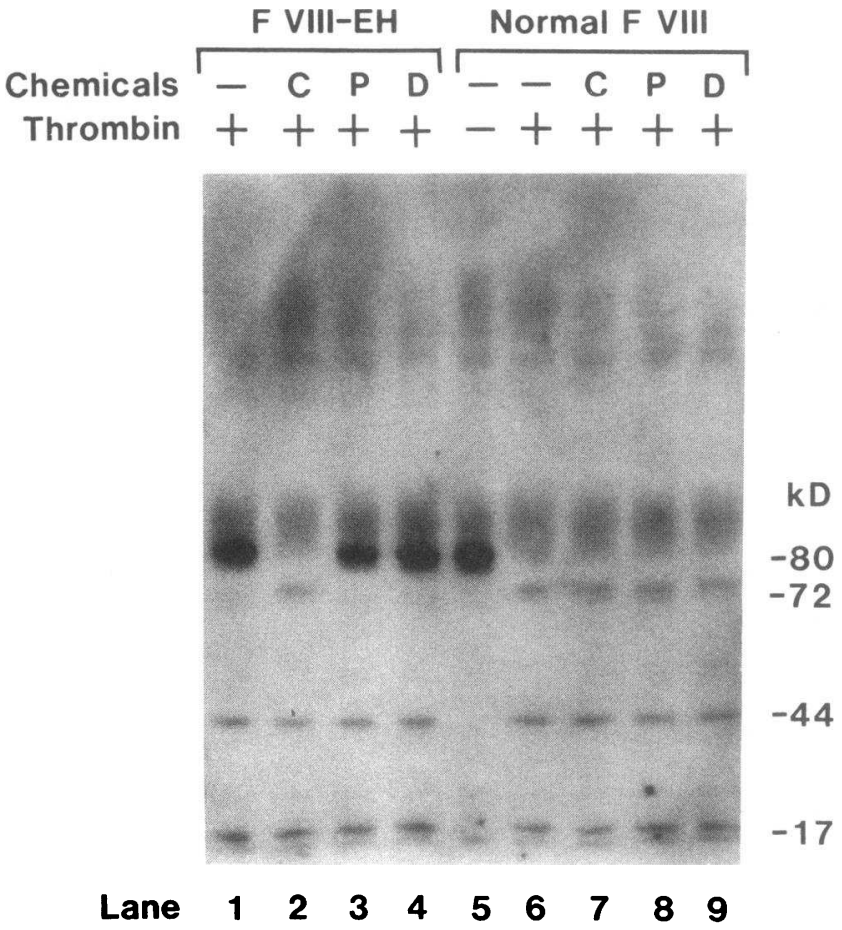

Figure 3. Immunoblots showing the effect of reducing agents on FVIII-EH light chain cleavage by thrombin. Immunoadsorbed factor VIII (2 U VIII:Ag) was incubated with cysteamine $(C)(10 \mathrm{mM}$ final concentration), penicillamine $(P)(80 \mathrm{mM})$, DTT $(D)(1 \mathrm{mM})$, or TBS for $30 \mathrm{~min}$ at $37^{\circ} \mathrm{C}$. The immunosorbent beads were then washed and treated with thrombin (10 U) or BBS for $60 \mathrm{~min}$ at room temperature before SDS elution. Analysis of the proteins following SDSPAGE and transfer to nitrocellulose was done with a mixture of three monoclonal anti-FVIII antibodies (27). In this experiment, ARC-5 was the FVIII-EH plasma analyzed. Comparable results were obtained with ARC-10.

suggested that the reduction and alkylation may have affected $\mathrm{vWf}$ multimer structure (30). To evaluate this hypothesis, normal vWf was added to the dialyzed plasmas after they had been incubated with DTT and IA. This consistently increased the amount of Factor VIII in the Vo fractions to over $40 \%$ of control values. While thrombin had the expected effect on Factor VIII elution when added to reduced and alkylated normal plasma that had been "reconstituted" with normal vWf, the addition of thrombin had no effect on FVIII-EH elution in similar experiments (Table I). Thus, there was no evidence of thrombin cleavage of the FVIII-EH light chain when DTT was added, as assessed by SDS-PAGE (Fig. 3) and by Factor VIIIvWf complex characterization (Table I). The increase in VIII:C that followed DTT addition to FVIII-EH plasma was more likely to be a result of DTT's effect on vWf structure, an effect that inhibited Factor VIII-vWf interaction.

The consistent low recovery of Factor VIII in Vo fractions for plasmas treated with DTT raised the possibility that part of the DTT effect might be on Factor VIII. This was not the case, for a Factor VIII concentrate with very low vWF (VIII:Ag/ $v W F: A g>50$ ) was detected in Vo fractions to an equivalent extent, whether or not it had been incubated with $5 \mathrm{mM}$ DTT (and dialyzed) before the addition of normal vWF and the gel filtration analysis. The DTT-treated samples had 92 and $94 \%$ of the amount of Vo Factor VIII as control samples, to which TBS was added instead of DTT. 
Table I. The Factor VIII Content of Void Volume Fractions

\begin{tabular}{|c|c|c|}
\hline \multirow{2}{*}{$\begin{array}{l}\text { Treatment of plasma } \\
\text { before gel filtration }\end{array}$} & \multicolumn{2}{|c|}{$\begin{array}{l}\text { Factor VIII in Vo fractions } \\
(\% \text { of control) }\end{array}$} \\
\hline & Normal plasma & FVIII-EH plasma \\
\hline Control (no additions) & 100 & 100 \\
\hline Thrombin (6 U/U VIII:Ag)* & 17 & 94 \\
\hline $\begin{array}{l}\text { Cysteamine }(10 \mathrm{mM} \text { final } \\
\text { concentration)* }\end{array}$ & 100 & 88 \\
\hline $\begin{array}{l}\text { Cysteamine followed by } \\
\text { thrombin }\end{array}$ & 20 & 16 \\
\hline $\begin{array}{l}\text { DTT ( } 5 \mathrm{mM} \text { final } \\
\text { concentration)* }\end{array}$ & 46 & 51 \\
\hline $\begin{array}{l}\text { DTT followed by thrombin } \\
\text { IA ( } 20 \mathrm{mM} \text { final concentration)* }\end{array}$ & 21 & 51 \\
\hline $\begin{array}{l}\text { after DTT } \\
\text { IA after DTT, followed by } \\
\text { dialysis and addition of } \\
\text { normal vWf }\end{array}$ & 17 & 15 \\
\hline $\begin{array}{l}\text { IA after DTT, followed by } \\
\text { dialysis, and addition of } \\
\text { normal vWf followed by } \\
\text { thrombin }\end{array}$ & 16 & 51 \\
\hline
\end{tabular}

* The addition of thrombin, cysteamine, DTT, or IA were each followed by a 30 -min incubation at $37^{\circ} \mathrm{C}$ before the next addition or the dialysis (see Methods for details).

Effect of $v$ Wf depletion on FVIII-EH procoagulant activity. Taken together, the data of Figs. 1 and 3 and Table I suggest that FVIII-EH has some VIII:C procoagulant function when DTT is added, even though the light chain remains resistant to thrombin cleavage. These data suggest that other methods that separate Factor VIII from vWf might also enhance FVIII-EH VIII:C function. To evaluate this possibility, vWf-free Factor VIII was prepared by immunoadsorption followed by high salt elution (28). The eluted fractions had no detectable vWf:Ag (i.e., $<0.1 \mathrm{U} / \mathrm{dl}$ ), but the eluted FVIII-EH had significant VIII:C activity (Fig. 4). The ratio of VIII:C to VIII:Ag in these FVIII-EH fractions was 0.31 , compared with 0.02 in the starting plasma sample. When normal plasma was chromatographed in the same way, the high salt eluate fractions had the same specific activity (VIII:C/VIII:Ag) as the starting plasma (Fig. $4 A$ ).

In order to establish that the generation of VIII:C activity was a specific result of vWF removal, control experiments were carried out in which other plasma proteins were removed from Vo FVIII-vWf complexes by $6 \%$ agarose gel filtration (Fig. 5). For normal plasma, the Vo fractions had comparable VIII:C, VIII:Ag, and vWf:Ag levels (Fig. $5 \mathrm{~A}$ ). However, no VIII:C (i.e., $<1 \mathrm{U} / \mathrm{dl}$ ) was detected in the Vo fractions when FVIII-EH was analyzed in the same way (Fig. $5 \mathrm{~B}$ ).

The fractions with peak activity were further characterized by incubating them with cysteamine, DTT, or BBS (Table II). While DTT had no effect on vWf-free FVIII-EH, cysteamine further increased the VIII:C level to $46 \mathrm{U} / \mathrm{dl}$. On the other hand, the addition of DTT generated VIII:C activity $(17 \mathrm{U} / \mathrm{dl})$ when the FVIII-EH-vWf complexes were tested. Cysteamine also increased the VIII:C activity of this fraction. At the concentrations used, neither reducing agent had a significant effect
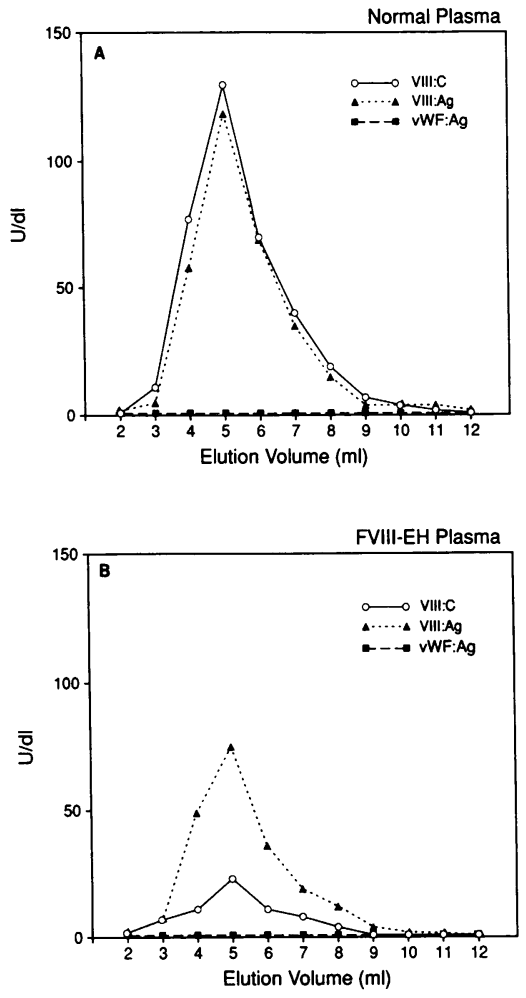

Figure 4. High salt elution of Factor VIII from an anti-vWf immunoadsorbent. $(A)$ normal plasma; (B) FVIII-EH $(A R C-5)$ plasma. After the immunoadsorbent beads were incubated with plasma, they were washed to remove unbound proteins and Factor VIII was eluted with $240 \mathrm{mM} \mathrm{Ca}^{2+}$ (see Methods). Fractions (1 $\mathrm{ml}$ ) following the start of the high salt elution are shown here. VIII:C was measured by chromogenic assay, and VIII:Ag and vWf:Ag by immunoradiometric assays.

on the VIII:C activity of fractions prepared from normal plasma.

\section{Discussion}

FVIII is modified by several proteolytic cleavages in a process that leads to activation and subsequent inactivation of its cofactor function (15, 31-33). Thrombin cleavages at arginine372 in the heavy chain and arginine-1689 in the light chain are
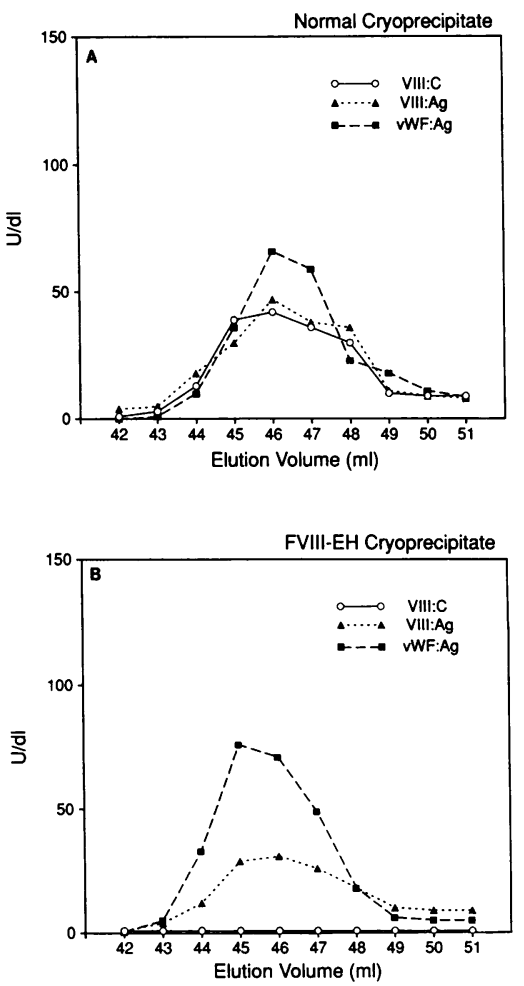

Figure 5. FVIII-vWf elution in the void volume after $6 \%$ agarose gel filtration. $(A)$ normal cryoprecipitate; $(B)$ FVIII-EH $(A R C-5)$ cryoprecipitate. Cryoprecipitate prepared from $5 \mathrm{ml}$ plasma was applied to a $1.6 \times 60$ $\mathrm{cm} 6 \%$ agarose column (see Methods). Only void volume fractions $(1 \mathrm{ml})$ are shown here. VIII:C was measured by chromogenic assay, and VIII:Ag and vWf:Ag by immunoradiometric assays. 


\begin{tabular}{|c|c|c|c|c|}
\hline \multirow[b]{3}{*}{ Treatment $^{\ddagger}$} & \multicolumn{4}{|c|}{ VIII:C/VIII:Ag (U/dl)* } \\
\hline & \multicolumn{2}{|c|}{$\begin{array}{l}\text { vWf-free Factor VIII } \\
\left(0.24 \mathrm{M} \mathrm{Ca}^{2+} \text { Eluate }\right)^{s}\end{array}$} & \multicolumn{2}{|c|}{$\begin{array}{c}\text { Factor VIII-vWf complexes } \\
\text { (Vo Fraction from } 6 \% \text { agarose gel filtration) }\end{array}$} \\
\hline & Normal plasma & FVIII-EH plasma & Normal plasma & FVIII-EH plasma \\
\hline Buffer & $87 / 119$ & $21 / 75$ & $39 / 47$ & $<1 / 31$ \\
\hline Cysteamine (10 mM) & 93/ND & $46 / \mathrm{ND}$ & 49/ND & $32 / \mathrm{ND}$ \\
\hline DTT (1 mM) & $82 / \mathrm{ND}$ & 23/ND & $34 / \mathrm{ND}$ & $17 / \mathrm{ND}$ \\
\hline
\end{tabular}

\begin{abstract}
* Untreated normal pooled plasma has (by definition) 100/100, while the ARC-5 FVIII-EH plasma used in this study had 2/87 (17). The maximum VIII:C/VIII:Ag levels when ARC-5 plasma was treated with cysteamine were 35/87 (21), and the maximum levels after incubation with DTT were $18 / 87$ (Fig. 2). ${ }^{\ddagger}$ An equal volume of cysteamine ( $10 \mathrm{mM}$ final concentration), DTT (1 mM), or buffer was added to an aliquot of the peak column fraction (see Figs. 4 and 5) for $30 \mathrm{~min}$ at $37^{\circ} \mathrm{C}$ before VIII:C chromogenic substrate assay. VIII:Ag was measured in the column fraction before the additions. ${ }^{\S}$ Aliquots of those column fractions with maximal VIII:C (0.24 M Ca ${ }^{2+}$ eluate, Fig. 4) or VIII:Ag (Vo fraction, Fig. 5) content were used in this experiment.
\end{abstract}

thought to be essential for Factor VIII procoagulant activity, as the substitution with isoleucine for either residue prevents thrombin activation and reduces procoagulant activity (34). In contrast, the substitution of lysine for arginine-1689 does not diminish Factor VIII activity or thrombin activation (34).

The substitution of cysteine for arginine-1689 in FVIII-EH abolishes an essential light chain thrombin cleavage site, and reduces its procoagulant activity (17). In recent studies, we have shown that the free thiol, cysteamine (beta-mercaptoethylamine), reacts with cysteine-1689 in FVIII-EH to form a new mixed disulfide, a pseudolysine that can be cleaved by thrombin to generate VIII:C activity (23).

In addition, other reducing agents, including DTT and penicillamine, increase FVIII-EH VIII:C activity (Figs. 1 and 2) in the absence of Factor VIII light chain cleavage by thrombin (Fig. 3 and Table I). The data summarized in Table I suggest that DTT-induced FVIII-EH VIII:C activity is due to the effect of this reducing agent on vWf multimer structure, rather than on FVIII-EH itself. This was verified by showing that FVIII-EH has VIII:C function ( $23 \mathrm{U} / \mathrm{dl}$ ) when separated from vWf(Fig. 4 $B$ ). Separation of Factor VIII-EH/vWf complexes from other plasma proteins did not generate VIII:C activity (Fig. 5 B) unless cysteamine or DTT was added (Table II), indicating that this is a specific effect of vWf removal.

The concept that light chain cleavage at residue 1689 is necessary only to separate vWf from Factor VIII has been suggested previously by Hill-Eubanks, et al. (16). Using a snake venom protease that cleaves the porcine Factor VIII heavy chain, but not its light chain, they showed that heavy chain cleavage alone generates an active porcine Factor VIII molecule when vWf is not present. They suggested that light chain cleavage at arginine-1689 is required only to dissociate vWf from Factor VIII, and that only heavy chain cleavage is required for procoagulant activity. Our data with human Factor VIII are consistent with this hypothesis. However, the FVIIIEH data in Table II indicate that there is a further VIII:C increase when both the heavy and the light chains are cleaved, e.g., when vWf-free FVIII-EH is incubated with cysteamine.

The moderately decreased specific activity of vWf-free FVIII-EH (23 U/dl VIII:C in a fraction with 75 U/dl VIII:Ag) could be due to several mechanisms. The increase in VIII:C when cysteamine is added to that fraction, to $46 \mathrm{U} / \mathrm{dl}$ (Table II), suggests that light chain cleavage at residue 1689 augments
VIII:C activity. The replacement of arginine- 1689 by cysteine may itself affect procoagulant function, either by reducing the rate at which thrombin cleaves the light chain cleavage or by some other effect on Factor VIII structure.

Our results may seem contrary to a previous report that there is no VIII:C activity when vWf is removed from a different mutant Factor VIII molecule that also has the arginine1689 to cysteine substitution (35). No procoagulant activity was detected by O'Brien and Tuddenham when they removed vWf from this CRM-positive plasma by an anti-vWf immunosorbent, and treatment with beta-mercaptoethanol did not generate VIII:C activity from separated Factor VIII-vWf complexes (35). The different results are not likely to be due to different vWf levels in the preparations, since the plasma samples were treated in similar ways. Moreover, similar assay methods were used to measure VIII:C. It is possible, however, that their patient's Factor VIII may differ at an as yet undefined polymorphism so that its properties are different from the CRM-positive molecules in the plasmas of our two FVIII-EH patients. This possibility is supported by the total absence of detectable VIII:C in patient $\mathrm{H} 10$ plasma $(35,36)$, while ARC-5 and ARC-10 plasmas have 2 and $5 \mathrm{U} / \mathrm{dl}$, respectively (17).

Studies of Factor VIII modified by site-directed mutagenesis have also been interpreted as demonstrating the need for two thrombin cleavages to obtain VIII:C activity. Pittman and Kaufman modified the thrombin cleavage sites at arginine-372 and arginine- 1689 by replacing them in separate constructs with isoleucine, and they found that both mutant molecules had a 20-fold reduction in VIII:C activity (34). It is likely, however, that $v W f$ present in the culture medium interacted with the mutant light chain, and this may have prevented the detection of VIII:C activity in the molecules modified at residue1689.

These data illustrate how the study of the natural Factor VIII mutations in CRM-positive patients can enhance our understanding of Factor VIII structure-function relationships. These experiments of nature provide an important adjunct to the analysis of normal proteins.

\section{Acknowledgments}

We thank Dr. Manoo Bhakta for providing ARC-10 plasma, Dr. Carol Fulcher for providing monoclonal antibody J16D-9, Dr. John Fenton 
for providing purified human thrombin, Dr. Dorothea Scandella for helpful discussions and manuscript review, and Debbie Wilder for manuscript preparation. These studies were supported by grants HL36099, HL-44336, and RR-05737 from the National Institutes of Health.

\section{References}

1. Hultin, M. B., and Y. Nemerson. 1978. Activation of factor $\mathrm{X}$ by factors IXa and VIII; a specific assay for factor IXa in the presence of thrombin-activated factor VIII. Blood. 52:928-940.

2. van Dieijen, G., G. Tans, J. Rosing, and H. C. Hemker. 1981. The role of phospholipid and factor VIIIa in the activation of bovine factor X. J. Biol. Chem. 256:3433-3442.

3. Owen, C. A., Jr., E. J. W. Bowie, and D. N. Fass. 1979. Generation of factor VIII coagulant activity by isolated, perfused neonatal pig livers and adult rat livers. Br. J. Haematol. 43:307-315.

4. Kaufman, R. J., L. C. Wasley, M. V. Davies, R. J. Wise, D. I. Israel, and A. J. Dorner. 1989. Effect of von Willebrand factor coexpression on the synthesis and secretion of factor VIII in Chinese hamster ovary cells. Mol. Cell. Biol. 9:1233-1242.

5. Weiss, H. J., I. I. Sussman, and L. W. Hoyer. 1977. Stabilization of factor VIII in plasma by the von Willebrand factor. J. Clin. Invest. 60:390-404.

6. Tuddenham, E. G. D., R. S. Lane, F. Rotblat, A. J. Johnson, T. J. Snape, S. Middleton, and P. B. A. Kernoff. 1982. Response to infusions of polyelectrolyte fractionated human factor VIII concentrate in human haemophilia A and von Willebrand's disease. Br. J. Haematol. 52:259-267.

7. Pittman, D. D., and R. J. Kaufman. 1989. Structure-function relationships of factor VIII elucidated through recombinant DNA technology. Thromb. Hae mostasis. 61:161-165.

8. Foster, P. A., C. A. Fulcher, R. A. Houghten, and T. S. Zimmerman. 1990 An immunogenic region within residues Val 1670-Glu 1684 of the factor VIII light chain induces antibodies which inhibit binding of factor VIII to von Willebrand factor. J. Biol. Chem. 263:5230-5234.

9. Precup, J. W., B. C. Kline, and D. N. Fass. 1991. A monoclonal antibody to factor VIII inhibits von Willebrand factor binding and thrombin cleavage. Blood. 77:1929-1936.

10. Lollar, P., D. C. Hill-Eubanks, and C. G. Parker. 1988. Association of the factor VIII light chain with von Willebrand factor. J. Biol. Chem. 263:1045110455.

11. Foster, P. A., C. A. Fulcher, R. A. Houghten, and T. S. Zimmerman. 1990. A synthetic factor VIII peptide of eight amino acid residues(1677-1684) contains the binding region of an anti-factor VIII antibody which inhibits the binding of factor VIII to von Willebrand factor. Thromb. Haemostasis. 63(3):403-406.

12. Hamer, R. J., J. A. Doedam, and N. H. Beeser-Visser. 1987. Factor VIII binds to von Willebrand factor via its Mr-80 000 light chain. Eur. J. Biochem. 166:37-43.

13. Davies, B. L., R. A. Furlong, and I. R. Peake. 1981. Studies on the relationship between factor VIII related antigen (VIIIRAg) and factor VIII clotting antigen (VIIICAg) by immunoelectrophoresis and autoradiography using ${ }^{125} \mathrm{I}$ anti-VIIICAg. Thromb. Res. 22:87-96.

14. Hamer, R. J., J. A. Koedam, N. H. Beeser-Visser, and J. J. Sixma. 1987. The effect of thrombin on the complex between factor VIII and von Willebrand factor. Eur. J. Biochem. 167:253-259.

15. Eaton, D., H. Rodriguez, and G. A. Vehar. 1986. Proteolytic processing of human factor VIII. Correlation of specific cleavages by thrombin, factor $\mathrm{Xa}$, and activated protein $\mathrm{C}$ with activation and inactivation of factor VIII coagulant activity. Biochemistry. 25:505-512.

16. Hill-Eubanks, D. C., C. G. Parker, and P. Lollar. 1989. Differential proteo- lytic activation of factor VIII-von Willebrand factor complex by thrombin. Proc. Natl. Acad. Sci. USA. 86:6508-6512.

17. Arai, M., M. Higuchi, S. E. Antonarakis, H. H. Kazazian, J. A. Phillips, R. L. Janco, and L. W. Hoyer. 1990. Characterization of a thrombin cleavage site mutation (Arg 1689 to Cys) in the factor VIII gene of 2 unrelated patients with cross reacting material positive hemophilia A. Blood. 75:384-389.

18. Hoyer, L. W., and R. T. Breckenridge. 1968. Immunologic studies of antihemophilic factor (AHF, factor VIII): cross-reacting material in a genetic variant of hemophilia A. Blood. 32:962-971.

19. Lazarchick, J., and L. W. Hoyer. 1978. Immunoradiometric measurement of the factor VIII procoagulant antigen. J. Clin. Invest. 62:1048-1052.

20. Weisgraber, K. H., T. L. Innerarity, and R. W. Mahly. 1981. Abnormal lipoprotein receptor binding activity of human $\mathrm{E}$ apoprotein due to cysteine-arginine interchange at a single site. J. Biol. Chem. 257:2518-2521.

21. Arai, M., A. M. Aly, and L. W. Hoyer. 1989. Cysteamine increases factor VIII-East Hartford (Arg-1689 to Cys) procoagulant activity. Blood. 74:35a (Abstr.)

22. Aly, A. M., and L. W. Hoyer. 1990. The substitution of cysteine for arginine-1689 in factor VIII-East Hartford reduces its procoagulant activity through formation of a disulfide bond. Clin. Res. 38:427a. (Abstr.)

23. Aly, A. M., and L. W. Hoyer. 1991. Factor VIII-East Hartford (Arg 1689 Cys) activity is enhanced by chemicals that lead to thrombin cleavage or dissociation from von Willebrand factor. Thromb. Haemostasis. 65:942. (Abstr.)

24. Breckenridge, R. T., and O. D. Ratnoff. 1962. Studies on the nature of the circulating anticoagulant directed against antihemophilic factor: with notes on an assay for antihemophilic factor. Blood. 20:137-149.

25. Seghatchian, M. J., and M. Miller-Anderson. 1978. A colorimetric evaluation of factor VIII:C potency. Med. Lab. Sci. 35:347-354.

26. Hoyer, L. W. 1972. Immunologic studies of antihemophilic factor (AHF, factor VIII). IV. Radioimmunoassay of AHF antigen. J. Lab. Clin. Med. 80:822833.

27. Arai, M., H. Inaba, M. Higuchi, S. E. Antonarakis, H. H. Kazazian, M. Fujimaki, and L. W. Hoyer. 1989. Direct characterization of factor VIII in plasma-Detection of a mutation altering a thrombin cleavage site (Arginine372-Histidine). Proc. Natl. Acad. Sci. USA. 86:4277-4281.

28. Tuddenham, E. G. D., N. C. Trabold, J. A. Collins, and L. W. Hoyer. 1979. The properties of factor VIII coagulant activity prepared by immunoadsorbent chromatography. J. Lab. Clin. Med. 93:40-53.

29. Cooper, H. A., F. F. Reisner, M. Hall, and R. H. Wagner. 1975. Effects of thrombin treatment on preparations of factor VIII and the $\mathrm{Ca} 2+$-dissociated small active fragment. J. Clin. Invest. 56:751-760.

30. Counts, R. B., S. L. Paskell, and S. K. Elgee. 1978. Disulfide bonds and the quaternary structure of factor VIII/von Willebrand factor. J. Clin. Invest. 62:702-709.

31. Fulcher, C. A., J. R. Roberts, and T. S. Zimmerman. 1983. Thrombin proteolysis of purified factor VIII procoagulant protein: Correlation of activation with generation of a specific polypeptide. Blood. 61:807-811.

32. Fulcher, C. A., J. R. Roberts, L. Z. Holland, and T. S. Zimmerman. 1985. Human factor VIII procoagulant protein. Monoclonal antibodies define precursor-product relationships and functional epitopes. J. Clin. Invest. 76:117-124.

33. Rotblat, F., D. P. O'Brien, F. J. O'Brien, A. H. Goodall, and E. G. D. Tuddenham. 1985. Purification of human factor VIII:C and its characterization by Western Blotting using monoclonal antibodies. Biochemistry. 24:4294-4300.

34. Pittman, D. D., and R. J. Kaufman. 1988. Proteolytic requirements for thrombin activation of anti-hemophilic factor (factor VIII). Proc. Natl. Acad. Sci. USA. 85:2429-2433.

35. O'Brien, D. P., and E. G. D. Tuddenham. 1989. Purification and characterization of factor VIII 1,689-Cys: A nonfunctional cofactor occurring in a patient with severe hemophilia A. Blood. 73:2117-2122.

36. Gitschier, J., S. Kogan, B. Levinson, and E. G. D. Tuddenham. 1988. Mutations of Factor VIII Cleavage Sites in Hemophilia A. Blood. 72:1022-1028. 